UDC 316.6

LBC 60.53

\title{
THE STRUCTURE OF URBAN IDENTITY OF THE VOLGOGRAD YOUTH
}

\author{
Anna A. Ozerina \\ Volgograd State University, Volgograd, Russian Federation
}

\begin{abstract}
The article presents the results of an empirical study of the structure of urban identity of young people. The relevance of the study is due to the fragmentary scientific knowledge of the concept of urban identity and the significant role of this phenomenon for the competent formation of the brand and image of the city. The practical implication of the study is mediated by the influence of the content and specificity of the formation of urban identity on the idea of a person's psychological and economic well-being within a certain place of residence, satisfaction with the quality of life, the level of tolerance and the characteristics of migration behavior. We based the empirical study on a combination of quantitative and qualitative methods of data collection revealing the semantic nature of the phenomenon of identity. The ratio and content of the main components of urban identity was measured with the help of questionnaires and psycho-semantic methods: the method "Who I am" by M. Kuhn and T. Mcpartland in the adaptation of T.V. Rumyantseva; method of writing compositions on the theme "My city"; a technique of unfinished sentences; questionnaire for collecting factual data, including the factors according to M. Lalli. The data obtained we processed through content analysis and descriptive statistics. As a result, the author described the main components of urban identity in the indigenous, living in Volgograd since birth, and nonindigenous residents of Volgograd - cognitive, emotional, motivational and behavioral. We also analyzed the content of the image of the city presented mainly in the minds of the Volgograd youth by the historical heritage of the city and its attractions; defined the attitude to the city, including feelings of different modality - from pride to resentment and anger; stated the features of migration behavior with contradictory content. The results can be taken into account both in the practice of social support of migrants, in the creation of programs of Patriotic education of young people, and in the process of creating a competent brand of Volgograd.
\end{abstract}

Key words: city identity, city consciousness, city brand, image of the city, city community, youth.

УДК 316.6

ББК 60.53

\section{СТРУКТУРА ГОРОДСКОЙ ИДЕНТИЧНОСТИ ВОЛГОГРАДСКОЙ МОЛОДЕЖИ}

\author{
Анна Александровна Озерина \\ Волгоградский государственный университет, г. Волгоград, Российская Федерация
}

\begin{abstract}
Аннотация. В статье представлены результаты эмпирического исследования структуры городской идентичности молодежи. Актуальность исследования обусловлена как фрагментарностью научного знания о понятии городской идентичности, так и значимой ролью этого феномена для грамотного формирования бренда и имиджа города. Практическая значимость исследования опосредована влиянием содержания и специфики формирования городской идентичности на представление человека о своем психологическом, экономическом благополучии в рамках определенного места жительства, удовлетворенность качеством жизни, уровень толерантности и особенности миграционного поведения. Эмпирическое исследование базировалось на сочетании количественных и качественных методов сбора данных, раскрывающее смысловую природу феномена идентичности. Соотношение и содержание основных компонентов городской идентич-

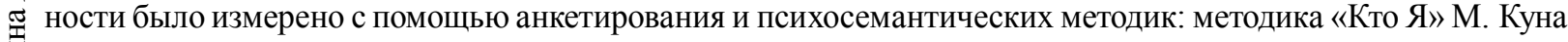
и Т. Макпартленда в адаптации Т.В. Румянцевой; метод написания сочинения по теме «Мой город»; методика незаконченных предложений; анкета для сбора фактических данных, включающая факторы по М. Лалли. () Полученные данные обработаны посредством контент-анализа и описательной статистики. В результате
\end{abstract}


были описаны основные компоненты городской идентичности у коренных, проживающих в Волгограде с рождения, и некоренных жителей Волгограда - когнитивный, эмоциональный, мотивационный и поведенческий. Также проанализировано содержание образа города, представленное преимущественно в сознании волгоградской молодежи историческим наследием города и его достопримечательностей; определено отношение к городу, включающее чувства разной модальности - от гордости до обиды и гнева; установлены особенности миграционного поведения, имеющего противоречивое содержание. Полученные результаты могут быть учтены как в практике социального сопровождения мигрантов, при создании программ патриотического воспитания молодежи, так и в процессе создания грамотного бренда Волгограда.

Ключевые слова: городская идентичность, городское самосознание, бренд города, имидж города, образ города, городская общность, молодежь.

Предметное поле феноменологии городской идентичности, как и методы ее исследования, в отечественной науке недостаточно определены. При этом тема восприятия городского пространства и ментальности носит междисциплинарный характер и представлена в ряде современных научных работ по социологии [5; 8; 12], экономике [7], философии [4], антропологии [3], культурологии [13] и психологии [10]. В отечественной и зарубежной науке история изучения проблемы городской идентичности прослеживается в работах о городской и региональной ментальности [1], средовой идентичности [15], территориальной идентичности [11]. Данное понятие также раскрывается через термины «идентичность города», «идентичность с городом», «городская ментальность», «идентичность места».

Изучение городской идентичности в целях углубления фундаментального научного знания объективно необходимо, но при этом особенно актуально смещение фокуса внимания на региональный аспект. В данном случае исследование будет носить прикладной характер и откроет возможности для повышения эффективности механизмов регулирования миграционных процессов, формирования позитивного имиджа города [9], воздействия на удовлетворенность жизнью жителей, создания грамотного бренда города.

Актуальность изучения городской идентичности волгоградской молодежи обусловлена также региональной спецификой. Неблагоприятная социально-экономическая ситуация в Волгоградской области, а именно - отрицательная динамика миграционных процессов за последние годы (по данным федеральной службы государственной статистики по Волгоградской области за 2012-2017 гг.), требует повышенного внимания к данной пробле- ме. Мы предполагаем, что эти процессы обусловлены также особенностями городской идентичности волгоградцев. Формирование негативной или нулевой (несформированной, размытой) идентичности зачастую провоцирует стратегию индивидуальной мобильности, состоящую в попытке сменить группу [14], в случае с городской идентичностью - переехать в другой город, а также сопровождается ощущением неполноценности и неудовлетворенности жизнью.

В широком смысле городская идентичность представляет собой выражение группового сознания в определенном историческом времени и пространстве $[1 ; 11]$. Самоидентификация горожанина происходит в определенном контексте и внедрена в конкретную физическую среду. В таком случае городская идентичность - это, прежде всего, вид социальной, а в более узком понимании - средовой идентичности. Г.М. Андреева отмечает, что основой средовой идентификации является непосредственная жизненная среда, приобретающая особое значение и наделяемая особым смыслом в исключительных случаях [2]. Отношения человека с окружающей средой во многом определяют содержание его идей, чувств, поведения и формирование личностной идентичности. Сформированная средовая идентичность, в том числе городская идентичность как ее компонент, обусловливает чувство стабильности, принятие определенной социальной роли и, соответственно, общественных правил, ценностей и норм.

Структура городской идентичности представлена эмоциональным, когнитивным, поведенческим и мотивационным компонентами. Эмоциональный компонент городской идентичности отражает отношение к городу и к себе как его жителю (положительное, негативное, 


\section{СОЦИОЛОГИЯ И СОЦИАЛЬНЫЕ ТЕХНОЛОГИИ}

нейтральное, смешанное), степень удовлетворенности городской жизнью, наличие интереса к истории и культурной жизни города, демонстрацию чувств к землякам. Когнитивный компонент содержит образ города и городского пространства, понимание его уникальности. Поведенческий компонент определяется наличием каких-либо действий, определяющих человека как горожанина. Мотивационный компонент отражается в виде намерений переехать из города или желании оставаться его жителем.

В данной работе представлены результаты эмпирического исследования, целью которого являлось уточнение структуры и содержания городской идентичности волгоградской молодежи. Для сбора эмпирических данных были применены: методика «Кто Я» М. Куна и Т. Макпартленда в адаптации Т.В. Румянцевой; метод написания сочинения по теме «Мой город»; методика незаконченных предложений; анкета для сбора фактических данных, включающая факторы по М. Лалли [16]. Обработка полученных данных производилась с помощью компьютерных программ Content Pro 1.6. и IBM SPSS Statistics v 22. Анализ и интерпретация осу- ществлялась посредством индуктивного контент-анализа и описательной статистики. Выборку исследования составило 150 респондентов мужского и женского пола в возрасте 20-25 лет, половина из них проживает в Волгограде с рождения, остальные родились в другой местности и пребывают в указанном городе не более 5 лет.

В ходе достижения поставленной цели сначала был выявлен ведущий компонент в структуре идентичности молодежи, проживающей в Волгограде. Исследование позволило установить, что по выборке у $44 \%$ респондентов лидирующим компонентом идентичности является «Социальное Я», у $56 \%$ - «Рефлексивное Я». То есть молодые люди, прежде всего, определяют себя через социальные роли (гендерную, семейную, учебно-профессиональную и т. д.) и индивидуально-личностные качества. Полученные результаты согласуются с методологическими основаниями понимания феномена идентичности, согласно которым при ее изучении прослеживается два основных аспекта - социальный и личностный [17]. Как правило, самоописание личности при ответе на вопрос происходит в этих двух аспектах.

Категории контент-анализа в группе коренных жителей

Таблицุа 1

\begin{tabular}{|l|c|}
\hline \multicolumn{1}{|c|}{ Единицы и категории анализа } & $\begin{array}{c}\text { Частота встречаемости } \\
\text { в группе коренных жителей, \% }\end{array}$ \\
\hline Историческое прошлое города («война», «Сталинград», «битва» и др.) & 1,27 \\
\hline $\begin{array}{l}\text { Положительные чувства по отношению к городу («нравится», «люблю»-0,57 \%; } \\
\text { гордость - 0,21 \%; спокойствие, ностальгия, гармония - 0,44 \%) }\end{array}$ & 1,22 \\
\hline $\begin{array}{l}\text { Описание проблем (экономический фактор - высокие цены, низкие зарплаты - } \\
0,40 \% \text { плохие дороги - 0,19\%; «грязь», «мусор» и т. п. - 0,35\%) }\end{array}$ & 1,18 \\
\hline Достопримечательности (Мамаев курган - 0,35 \%; памятники - 0,20\%; Волга - 0,20\%) & 0,99 \\
\hline Упоминание жителей города & 0,71 \\
\hline Положительные описания города («родной», «великий», «прекрасен») & 0,66 \\
\hline Отрицательные чувства по отношению к городу (сожаление, грусть, обида, стыд) & 0,42 \\
\hline ЧМ по футболу 2018 & 0,42 \\
\hline Желание уехать («уеду», «сбежать», «убежать») & 0,24 \\
\hline
\end{tabular}

Категории контент-анализа в группе некоренных жителей

\begin{tabular}{|l|c|}
\hline \multicolumn{1}{|c|}{ Категории и единицы анализа } & $\begin{array}{c}\text { Частота встречаемости в группе } \\
\text { некоренных жителей, \% }\end{array}$ \\
\hline Историческое прошлое города («история», «война», «битва» и др.) & 2,29 \\
\hline $\begin{array}{l}\text { Достопримечательности (Мамаев курган - 0,30 \%; памятники - 0,30 \%; Волга - } \\
0,30 \% ; \text { Аллея Героев - 10 \%; и др.) }\end{array}$ & 0,76 \\
\hline Положительные описания города («красивый», «прекрасный», «замечательный») & 0,76 \\
\hline Инфраструктура (вузы, заводы, транспорт, кафе и др.) & 0,71 \\
\hline Упоминание жителей города & 0,38 \\
\hline Негативные описания города («бесперспективный», «неразвивающийся», «грязный») & \\
\hline
\end{tabular}


Далее был определен вес городской идентичности молодежи в структуре социальной. В результате установлено, что определение себя как жителя города встречается в ответах респондентов реже всего. Только в $24 \%$ определений себя обнаружены индикаторы городской идентичности («Я - волгоградец», «Я житель Волгограда», «Я - житель одного из районов Волгограда»), в оставшихся $76 \%$ случаев нет определений себя в терминах принадлежности к городу. Другими словами, осознание себя как жителя Волгограда является скорее незначимой составляющей структуры социальной идентичности волгоградской молодежи. При этом не обнаружено зависимости наличия подобных характеристик от места рождения и длительности проживания в Волгограде. Коренные и некоренные жители в равной степени определяют и не определяют себя как жителя города.

На следующем этапе была проанализирована структура городской идентичности молодежи. Анализ позволил зафиксировать незначительные различия в группе коренных и некоренных жителей. Для наглядности в таблицах 1 и 2 представлены кодировочные матрицы с выделенными ведущими категориями, встречающимися в описаниях города.

Частота встречаемости категорий анализа представлена в разных таблицах, поскольку объем текстов сочинений по теме «Мой город» у коренных и некоренных жителей различается, кроме того, нами не вычислялась значимость полученных различий. Более того, установлено, что содержательно выявленные категории имеют незначительные отличия друг от друга в этих двух группах. Например, категория «инфраструктура» обнаружена только в ответах некоренных жителей.

Как видно из таблиц, больший вес из числа значимых для нашего исследования категорий составили описания исторического прошлого города. Формальными признаками данной категории являлось присутствие лексики, используемой респондентами для описания исторических фактов, своего эмоционального отношения к ним. В качестве единиц анализа и эмпирических индикаторов выступили такие понятия как «история города», «Царицын», «Великая Отечественная война», «Сталинградская битва», «солдаты», «побе- да», «погибшие» и другие. В качестве основного события, значимого в масштабах страны и отраженного в сознании горожан, выступает победа в Сталинградской битве. Для характеристики этой категории приведем отрывок из текста респондента: «Я живу здесь с самого рождения и все больше испытываю желание изучать его историю. Раньше я думала, что это глупо, но сейчас я могу пройтись по Мамаеву Кургану и назвать десятки фамилий, которые оставили память о себе в этом городе навсегда. Да, Сталинградская битва - важная часть в истории Волгограда, но я изучала глубже, я изучала историю города Царицына - великой губернии, одной из самых крупных губерний России. И я люблю свой город, так как знаю больше других его жителей, когда я проезжаю по улицам Волгограда - я прорисовываю в голове картину того, как здесь было все раньше».

Весомой категорией в группе коренных жителей оказались также «положительные чувства по отношению к городу» и «описание проблем города». В качестве наиболее часто описываемых чувств по отношению к городу у этой группы встречаются любовь и гордость. Последнее в основном связано с историей города: «Волгоград - город с великой историей и известными людьми. При общении с иногородними людьми появляется чувство гордости за свою малую родину. При рассказе о Мамаевом кургане, Доме Павлова, и других памятниках Великой Отечественной войны захватывает невероятное ощущение принадлежности к этому великому городу». Согласно Е.П. Ильину, переживая эмоции, связанные с гордостью, человек осознает собственную значимость, даже если это чувство касается не его личных достижений, а достижений близкого ему человека или референтной группы [6]. Гордость тесно связана с так называемым чувством собственного достоинства, она проявляется в потребности уважения окружающими людьми. Другими словами, гордость за свой город актуализируется при его сравнении с другими, необходимостью признания и положительной оценки со стороны приезжих и туристов. Скорее всего, историческое прошлое города позволяет реализовать потребность в уважении и проявить патриотизм. 
Про любовь респонденты говорят, указывая, что Волгоград им родной. То есть, скорее всего, положительные чувства по отношению к городу базируются на своем индивидуальном опыте, прошлом, связанным с городским пространством.

Категория «описание проблем города» раскрывается в основном в таких социальноэкономических индикаторах, как безработица, низкий уровень жизни, высокий уровень цен и так далее. На втором месте респонденты указывают на плохое состояние дорог в городе: «К сожалению, многим наш город известен именно как “Город без дорог”». Важно отметить, что коренные жители в основном описывают именно проблемы города, не приписывая ему негативные характеристики в виде прилагательных, как это делают некоренные жители. При этом данные описания содержат эмоциональный компонент, указание на свои чувства по отношению к перечисленным проблемам: «К сожалению, руководство города никак не способствует его развитию. Да, ЧМ-2018, новый стадион, новые гостиницы, а дальше что? У нас в городе все постепенно умирает, как в целом во всей стране. Нормальные поликлиники? А как это? Чистые улицы? Только не здесь! Адекватная молодежь? Это не про нас! Происходит какое-то сумасшествие среди людей: начиная от дохлых собак и использованных презервативов возле родников и заканчивая свалками посреди кладбища, причем среди отходов не венки и старые надгробия, а пищевые отходы, привезенные из частных близлежащих жилых секторов. И нет, самое грустное, что я не утрирую».

Некоренное население в основном акцентирует внимание на проблемах через негативные характеристики самого города, например: «бесперспективный», «неразвивающийся», «грязный». Выявленное различие можно объяснить тем, что у коренных жителей проблемы города отражены в эмоциональном и поведенческом компонентах городской идентичности, а у некоренных - в когнитивном, как завершенный образ города.

Категория «Достопримечательности» имеет больший вес в текстах некоренных жителей, хотя в сочинениях коренного населения она тоже присутствует. В качестве основных городских ориентиров, по которым место узнают за его пределами и выстраивается образ Волгограда в сознании молодежи, выступают Мамаев Курган и река Волга. Респонденты также указывают на наличие памятников в городе, посвященных Великой Отечественной войне.

Положительные описания города присутствуют в текстах и коренных, и некоренных жителей Волгограда. Наиболее популярными характеристиками являются «великий» (отражает историческое прошлое - участие в Великой Отечественной войне), «красивый», «прекрасный». В описаниях коренных жителей наиболее популярна характеристика «родной»: «Этот город пророс во мне, это именно мое место каждой клеточкой тела, здесь все родное до судорог в ногах. Я не знаю, уеду ли отсюда в будущем, но если уеду, то обязательно вернусь - я хочу быть похоронена на родной Волгоградской земле».

Также в текстах коренных жителей часто встречаемой категорией является «Описание отрицательных чувств по отношению к городу». Но это не ярко выраженные эмоции, a скорее общий фон отношения. Эмпирическими индикаторами выступили такие слова, как «сожаление», «обидно», «грустно»: «Очень обидно, что такой великий город имеет такую позорную славу».

Перечисленные описания составляют когнитивно-эмоциональный компонент городской идентичности.

Среди основных категорий, определяющих городскую идентичность, выделяется «жители города». При анализе данной категории возникли сложности из-за ее употребления респондентами в разных контекстах. Ее место в структуре городской идентичности требует дальнейшего изучения.

Важной отличительной особенностью текстов некоренных жителей является наличие показателей инфраструктуры города. Данная категория эмпирически выражена словами «заводы», «вузы», «кинотеатры» и так далее. Примечательно, что у коренного населения указанных признаков не встречается. Этоможет быть связано с тем, что у некоренных жителей более выражены механизмы сравнения при построении городской идентичности. Они сравнивают Волгоград с прежним местом проживания. При этом большинство рес- 
пондентов нашей выборки оказались из сельской местности, где инфраструктура менее развита, что приводит к важности ее роли при построении образа города.

Мотивационный компонент городской идентичности у коренных жителей Волгограда представлен в виде выражения намерений переехать в другой город. Причем некоторые респонденты используют ярко окрашенные словосочетания «сбежать отсюда», «убежать из этого города».

Наконец, у коренных жителей проявилась такая категория, как «Чемпионат мира по футболу 2018». Данному событию, которое на момент проведения исследования еще не состоялось, сложно найти место в структуре городской идентичности волгоградцев, но с ним связаны эмоциональные и поведенческие составляющие. «В 2018 г. в Волгограде пройдет Чемпионат мира по футболу, где соберется очень много гостей. Я надеюсь, что мой город и сами волгоградцы смогут достойно принять Чемпионат и доказать, что Волгоград - это город, которым действительно можно гордиться».

Для содержательного наполнения структурных компонентов городской идентичности волгоградской молодежи нами были проанализированы данные, полученные с помощью методики «Незаконченные предложения».

Во-первых, был проанализирован эмоциональный компонент, который включал в себя ответы, характеризующие отношение к Волгограду, к себе как его жителю, удовлетворенность или неудовлетворенность городской жизнью, проявление или отсутствие интереса к истории и культурной жизни города, демонстрацию чувств по отношению к землякам.

Нами установлено четыре типа модальности городской идентичности: положительная, негативная, нейтральная или спутанная (диффузная). Мы проследили ведущую модальность идентичности по выборке (табл. 3).

Таблица 3

Модальность городской идентичности волгоградской молодежи

\begin{tabular}{|c|c|c|c|}
\hline Положительная & Негативная & Нейтральная & Спутанная \\
\hline $47,1 \%$ & $23,5 \%$ & $15,7 \%$ & $11,8 \%$ \\
\hline
\end{tabular}

У половины респондентов выборки зафиксирована позитивная городская идентич- ность, которая выражена в принятии города, положительных чувствах по отношению к городу и его жителям: «Волгоград у меня вызывает чувство душевной привязанности, родства». Треть выборки продемонстрировала негативную городскую идентичность, которая основана на чувствах стыда, раздражения, брезгливости и других, связанных с городским пространством и населением: «Волгоград у меня вызывает чувство разочарования» или «Волгоград у меня вызывает чувство тоски, а иногда отвращения». Нейтральная городская идентичность обнаружена у $15,7 \%$ респондентов. Она отражает выраженное безразличие по отношению к городу: «Быть жителем Волгограда для меня значит жить в этом городе». Меньший процент выборки обладает спутанной городской идентичностью, которая основана на противоречивых чувствах, например, гордости за историю города и стыда за поведение его жителей.

Во-вторых, было определено содержание когнитивного компонента городской идентичности волгоградской молодежи. Образ городского пространства складывается из осознания ими исторического прошлого города (описания связаны с участием и победой в Великой Отечественной войне). Данный факт был обнаружен нами и в текстах сочинений респондентов. Акцент при описании города и его отличительных особенностей также ставится на наличии в нем проблем. Среди них выделяются часто и ярко описываемые: отсутствие хорошего дорожного покрытия, низкий социально-экономический уровень жизни, грязные улицы, транспортная проблема и другие. «В отличие от жителей других городов, волгоградцы знают, что такое плохие дороги».

Поведенческий компонент не был нами достаточно прослежен. Другими словами, стимульный материал, используемый нами посредством методики «Незаконченные предложения» не активизировал проявление поведенческого компонента городской идентичности. Возможно, необходим пересмотр предъявляемых стимулов, либо существует проблема наличия данного компонента в сознании опрошенных. Тем не менее респонденты отмечают, что механизмы сравнения (при общении с жителями других городов), чувство общности переживания происходящего (при 
посещении городских мероприятий) позволяют почувствовать себя жителем города. То есть субъектное начало присутствует в содержании городской идентичности, но для изучения его особенностей требуются дополнительные исследования.

Мотивационный компонент также нами был вычислен количественно. Желание и планы переехать из Волгограда высказали 40 \% респондентов, оставшиеся $60 \%$ не имеют подобных намерений. При этом важным является тот факт, что предложение «Я бы всегда хотел жить в ...» только $20 \%$ человек закончили фразой «в Волгограде». Остальные 80 \% опрошенных перечисляли много других вариантов городов России и стран. Иначе говоря, сформированнность мотивационного компонента городской идентичности волгоградской молодежи находится на низком уровне.

Таким образом, городская идентичность, как вид социальной идентичности волгоградской молодежи, занимает второстепенное место в ее структуре. У молодежи, проживающей с рождения в Волгограде, структура городской идентичности представлена в большей мере эмоциональным и когнитивным компонентами, в меньшей - мотивационным компонентом. Характеристики поведенческого компонента не были зафиксированы. В группе молодежи, живущей в Волгограде не больше пяти лет, наиболее ярко выражен и содержательно наполнен только когнитивный компонент.

Содержательным ядром, определяющим когнитивный компонент городской идентичности молодежи Волгограда, являются представления об историческом военном прошлом города. Эмоциональный компонент городской идентичности жителей представлен чувствами гордости и родства. Эти чувства являются основой позитивной городской идентичности волгоградцев, которая зафиксирована у половины респондентов выборки. Негативная городская идентичность непосредственно связана с образом города (когнитивном компонентом) и выражается в форме гнева и обиды. Мотивационный компонент городской идентичности определяет миграционную тенденцию. В проведенном исследовании она оказалась противоречивой - намерений переехать молодежь не высказывает, но желание жить в Волгограде также не демонстрирует.
Поведенческий компонент городской идентичности волгоградской молодежи содержательно не проявился в исследовании.

\section{СПИСОК ЛИТЕРАТУРЫ}

1. Акопов, С. В. Человек многомерный: транснациональная модель идентификации с макрополитическими сообществами (метатеоретический анализ) / С. В. Акопов. - СПб : Алетейя, 2015. -296 с.

2. Андреева, Г. М. К вопросу о кризисе идентичности в условиях социальных трансформаций / Г. М. Андреева // Психологические исследования : электрон. науч. журн. - 2011. - № 6 (20). - С. 1. Электрон. текстовые дан. - Режим доступа: http: //psystudy.ru/index.php/num/2011n6-20/580 (дата обращения: 10.08.2018). - Загл. с экрана.

3. Антропологическое понимание города и методология урбанистического изучения / Ю. П. Шабаев, А. П. Садохин, О. В. Лабунова, Н. Н. Сазонова // Мониторинг общественного мнения: Экономические и социальные перемены. - 2018. - № 3 (145). C. 248-267. -DOI: 10.14515/monitoring.2018.3.13.

4. Балюшина, Ю. Л. Самодеструкция личности как индикатор несовершенства социокультурного пространства провинциального города (на примере Вологодской области) / Ю. Л. Балюшина // Теория и практика общественного развития. 2015. - № 18. - C. 257-261.

5. Горнова, Г. В. Коллективная память и практики коммеморации в формировании городской идентичности / Г. В. Горнова // Вестник Омского государственного педагогического университета. Гуманитарные исследования. - 2017. - № 2 (15). C. $18-21$.

6. Ильин, Е. П. Эмоции и чувства / Е. П. Ильин. - СПб : Питер, 2001. - 752 с.

7. Муравьева, Н. Н. Формирование городского бренда на примере Ростова-на-Дону / Н. Н. Муравьева // Архонт. - 2018. - № 1 (4). - С. 61-65.

8. Правоторова, А. А. Теоретические основания исследования городской идентичности / А. А. Правоторова, У. Г. Кондратьева // Творчество и современность. - 2018. - № 2 (6). - С. 69-79.

9. Понукалина, О. В. Имидж территории в контексте повышения привлекательности региона / О. В. Понукалина, Л. В. Логинова // Вестник Волгоградского государственного университета. Серия 7, Философия. Социология и социальные технологии. - 2016. - № 1 (31). - С. 65-72. -DOI: http://dx.doi.org/10.15688/jvolsu7.2016.1.9.

10. Савина, О. О. Средовые условия в формировании городской идентичности новых жителей мегаполиса / О. О. Савина, В. А. Баранова // Психо- 
логия. Историко-критические обзоры и современные исследования. - 2017. - Т. 6, № 2А. - С. 171-180.

11. Самошкина, И. С. Территориальная идентичность как предмет социально-психологического исследования / И. С. Самошкина // Вестник РГГУ. Серия «Психология. Педагогика. Образование». 2008. - № 3. - С. 43-53.

12. Сосновская, А. М. Нематериальное наследие и идентичность молодежи Санкт-Петербурга /А. М. Сосновская, А. В. Михайлов, О. Ю. Орлова // Управленческое консультирование. - 2018. № 2 (110). - С. 88-99.

13. Федотова, Н. Г. Городская идентичность как конкурентное преимущество территории / Н. Г. Федотова // Ярославский педагогический вестник. 2016. - № 5. - С. 372-377.

14. Янгирова, С. М. Социальная идентичность: общие проблемы / С. М. Янгирова // Исторические, философские, политические и юридические науки, культурология и искусствоведение. Вопросы теории и практики. - 2011. - № 2 (8), ч. 2. - С. 203-207.

15. Identity and the natural environment: The psychological significance of nature / ed. by S. D. Clayton, S. Opotow. - Cambridge : MIT Press, 2003. $-353 \mathrm{p}$.

16. Lalli, M. Urban-related identity: Theory, measurement, and empirical findings / M. Lalli // Journal of Environmental Psychology. - 1992. - Vol. 12 (4). P. $285-303$.

17. Tajfel, H. The achievement of group differentiation / H. Tajfel // Differentiation between social groups. Studies in the social psychology of intergroup relations. - L. : Academic Press, 1978. P. 77-98.

\section{REFERENCES}

1. Akopov S.V. Chelovek mnogomernyy: transnatsionalnaya model identifikatsii $s$ makropoliticheskimi soobshchestvami (metateoreticheskiy analiz) [Multidimensional Person: Transnational Model of Identification with Macropolitical Communities (the Metatheoretical Analysis)]. Saint Petersburg, Aleteya Publ., 2015.296p.

2. Andreeva G.M. K voprosu o krizise identichnosti v usloviyakh sotsialnykh transformatsiy [On the Issue of Identity Crisis in the Conditions of Social Transformations]. Psikhologicheskie issledovaniya: elektronnyy nauchnyy zhurnal, 2011, no. 6 (20). URL: http://psystudy.ru/index.php/num/ 2011n6-20/580 (accessed 10 August 2018).

3. Shabaev Yu.P., Sadokhin A. P., Labunova O.V., Sazonova N.N. Antropologicheskoe ponimanie goroda i metodologiya urbanisticheskogo izucheniya [Anthropological understanding of the city and methodology of urbanistic studying]. Monitoring obshchestvennogo mneniya: Ekonomicheskie $i$ sotsialnye peremeny [Monitoring of Public Opinion: Economic and Social Changes], 2018, no. 3 (145), pp. 248-267. DOI: 10.14515/monitoring.2018.3.13.

4. Balyushina Yu.L. Samodestruktsiya lichnosti kak indikator nesovershenstva sotsiokulturnogo prostranstva provintsialnogo goroda (na primere Vologodskoy oblasti) [Personal Self-Destruction as an Indicator of Sociocultural Imperfection of Provincial Cities (the Case Study of the Vologda Region)]. Teoriya i praktika obshchestvennogo razvitiya [Theory and Practice of Social Development], 2015, no. 18, pp. 257-261.

5. Gornova G.V. Kollektivnaya pamyat i praktiki kommemoratsii v formirovanii gorodskoy identichnosti [Collective Memory and Practices of Commemoration in the Formation of City Identity]. Vestnik Omskogo gosudarstvennogo pedagogicheskogo universiteta. Gumanitarnye issledovaniya, 2017, no. 2 (15), pp. 18-21.

6. Ilyin E.P. Emotsii i chuvstva [Emotions and Feelings]. Saint Petersburg, Piter Publ., 2001. 752 p.

7. Muravyeva N.N. Formirovanie gorodskogo brenda na primere Rostova-na-Donu [Formation of a City Brand on the Example of Rostov-on-Don]. Arkhont, 2018, no. 1 (4), pp. 61-65. DOI: 10.24411/2587-94642018-00009.

8. Pravotorova A.A., Kondratyeva U.G. Teoreticheskie osnovaniya issledovaniya gorodskoy identichnosti [Theoretical Bases of City Identity Research]. Tvorchestvo i sovremennost, 2018, no. 2, pp. 69-79.

9. Ponukalina O.V., Loginova L.V. Imidzh territorii $\mathrm{v}$ kontekste povysheniya privlekatelnosti regiona [Image of the Territory in the Context of Increasing Attractiveness of the Region]. Vestnik Volgogradskogo gosudarstvennogo universiteta. Seriya 7, Filosofiya. Sotsiologiya i sotsialnyye tekhnologii [Science Journal of Volgograd State University. Philosophy. Sociology and Social Technologies], 2016, no. 1 (31), pp. 65-72. DOI: http:// dx.doi.org/10.15688/jvolsu7.2016.1.9.

10. Savina O.O., Baranova V.A. Sredovye usloviya $\mathrm{v}$ formirovanii gorodskoy identichnosti novykh zhiteley megapolisa [Environmental Conditions in the formation of City Identity of New Residents of Megalopolis]. Psikhologiya. Istorikokriticheskie obzory i sovremennye issledovaniya [Psychology. Historical and Critical Reviews and Modern Research], 2017, vol. 6, no. 2a, pp. 171-180.

11. Samoshkina I.S. Territorialnaya identichnost kak predmet sotsialno-psikhologicheskogo issledovaniya [Territorial Identity as a Subject of Social and Psychological Research]. Vestnik RGGU. Seriya «Psikhologiya. Pedagogika. Obrazovanie», 2008, no. 3, pp. 43-53.

12. Sosnovskaya A.M., MikhaylovA.V., Orlova O.Yu. Nematerialnoe nasledie i identichnost molodezhi 


\section{СОЦИОЛОГИЯ И СОЦИАЛЬНЫЕ ТЕХНОЛОГИИ}

Sankt-Peterburga [Non-Material Heritage and Identity of Youth of St. Petersburg]. Upravlencheskoe konsultirovanie, 2018, no. 2 (110), pp. 88-99.

13. Fedotova N.G. Gorodskaya identichnost kak konkurentnoe preimushchestvo territorii [City Identity as Competitive Advantage of the Territory]. Yaroslavskiy pedagogicheskiy vestnik, 2016, no. 5, pp. 372-377.

14. Yangirova S.M. Sotsialnaya identichnost: obshchie problemy [Social Identity: Common Problems]. Istoricheskie, filosofskie, politicheskie i yuridicheskie nauki, kulturologiya i iskusstvovedenie. Voprosy teorii i praktiki, 2011, no. 2 (8), Part 2, pp. 203-207.
15. Clayton S. D., Opotow S., eds. Identity and the natural environment: The psychological significance of nature. Cambridge, Mit Press, 2003. $353 \mathrm{p}$.

16. Lalli M. Urban-related identity: Theory, measurement, and empirical findings. Journal of Environmental Psychology, 1992, vol. 12 (4), pp. 285-303.

17. Tajfel $\mathrm{H}$. The achievement of group differentiation. Differentiation between social groups. Studies in the social psychology of intergroup relations. London, Academic Press, 1978, pp. 77-98.

\section{Information about the Author}

Anna A. Ozerina, Candidate of Sciences (Psychology), Associate Professor of Department of Psychology, Volgograd State University, Prosp. Universitetsky, 100, 400062 Volgograd, Russian Federation, ozerinskaya@volsu.ru.

\section{Информация об авторе}

Анна Александровна Озерина, кандидат психологических наук, доцент кафедры психологии, Волгоградский государственный университет, просп. Университетский, 100, 400062 г. Волгоград, Российская Федерация, ozerina@volsu.ru. 